\title{
Staff education
}

\author{
E C Smith, A H Kendrick, A Brewin
}

The quantity and quality of the drug delivered from a nebuliser is to some extent dependent on the operator. ${ }^{1}$ Several reports have highlighted deficiencies in the provision of nebuliser treatment in hospitals. ${ }^{2-5}$ Education of those involved in prescribing, supplying, and supervising nebulised therapy is therefore essential. Health carers dealing with nebuliser therapy should have the required knowledge and skills to provide an optimal service. Those who are in charge of running a nebuliser service have the responsibility for organising a training programme at a local level and therefore have to have the required education to train people with the primary responsibility in caring for these patients.

\section{Training programmes}

In the UK the registered training for physiotherapists, nurses, respiratory technicians, and clinical scientists all cover nebuliser therapy. In addition, there are various respiratory training courses in physiotherapy, nursing, and physiological respiratory measurements. Standards for the measurement of respiratory function have been produced by the British Thoracic Society and the Association of Respiratory Technicians and Physiologists. ${ }^{6}$

Training programmes should include instruction on lung function testing equipment measurements of lung function, drugs and delivery devices, patient assessment and education.

\section{Lung function equipment}

INSTRUMENTS

Staff should understand the instruments that can be used to measure dynamic lung volumes and flows, their advantages and disadvantages. Instruments studied should include Wright's peak flow meter and the mini-Wright, wedge bellows spirometers, and portable electronic spirometers.?

Medicine, clo

Department, Bristol

Royal Infirmary,

Bristol BS2 8HW, UK

E C Smith

Respiratory

Department, Bristo

Royal Infirmary,

A H Kendrick

Chest Unit, Kent and

Sussex Hospital,

Tunbridge Wells, Kent

A Brewin

Correspondence to:
Ms E C Smith.

Staff should also understand the importance of routine maintenance and calibration of each instrument used to measure dynamic lung volumes and flows and have actively practised maintenance and calibration programmes.

Measurements of respiratory function

Staff should understand and be able to define the measurements that can be made: forced expiratory volume in one second $\left(\mathrm{FEV}_{1}\right)$, vital capacity (VC), forced vital capacity (FVC), and peak expiratory flow (PEF). They should be able to obtain these measurements from recordings made before and after administration of a bronchodilator and select the most appropriate measurements, presenting them in an acceptable form. ${ }^{8}$ They should be able to differentiate between poor patient performance, disordered lung function, or a deterioration in clinical status.

Staff should be able to instruct patients in the use and cleaning of equipment. They should then instruct staff on how to record results, both in the laboratory and in the domiciliary measurement of lung function before and after appropriate prescribed treatment.

\section{Respiratory function}

Staff should understand the normal function of the airways. This should include the normal anatomy and physiology of the airways, with emphasis on their mechanical function, and how to use the expertise of a respiratory function technician when required.

\section{PATHOPHYSIOLOGY}

Staff should understand the pathophysiological changes that occur in intrathoracic airflow obstruction, interstitial lung disease, and other such disorders of lung function that may require inhaled therapy (such as cystic fibrosis). They should understand how the measurement of respiratory function can assist in the diagnosis and subsequent management of these disorders.

\section{Drugs and delivery devices}

PHARMACOLOGY

Staff should understand the different types of inhalers and nebuliser solutions in terms of their mode of action, aerosol deposition in the airways and side effects, and be aware of the usual dosage of bronchodilator drugs and other drugs commonly administered by nebuliser. ${ }^{9}$
Staff should understand the principle of operation of hand held inhalation devices, including spacer and aerosol "saving" devices, and how to use each of these devices correctly. They should be able to select the device most suitable for the patient's needs and abilities, and should understand the principles of operation of jet and ultrasonic nebulisers and the various as- 
domiciliary nebuliser/compressor systems for bronchodilators and other medications, including what advice to give when systems malfunction and the importance of clear instructions when nebulisers do not provide expected symptom relief.

Patient assessment and education

A sound knowledge of how patients should be assessed for nebuliser treatment is importan (see papers on asthma and COPD). Staff must be able to instruct patients in nebuliser use and be familiar with and provide all written instructions. To instruct staff and then patients in this way takes time, specific knowledge, and communication skills. Funding of a local nebuliser service should take this into account ${ }^{10}$
Newman SP. Efficient use of nebulizers. Update 1988:36: 381-8.
Caldwell NA, Milroy R, McCabe J, Banham SW, Moran F. An audit of nebulisation techniques in a major teaching 8.
Stainforth JN, Lewis RA, Tattersfield AE. Dosage and
delivery of nebulised beta-agonists in hospital. Thorax delivery of nebulised beta-agonists in hospital. Thorax
1983;38:751-4. 4 Caldwell NA, Milroy R. Optimizing nebulization practice within a large teaching hospital: easier said than done.
Respir Med 1995;89:57-9. 5 Craig IR, Riley MR, Cooke NJ. Prescribing of nebulized bronchodilators - can we change bad habits? Respir Med
1989;83:33-4. British Thoracic Society and Association of Respiratory Technicians and Physiologists. Guidelines for the
measurement of respiratory function. Respir Med 1994 88: $165-94$.
Kendrick AH, Smith EC. Simple measurements of lung Kendrick AH, Smith EC. Simple measurements of lung
function. Professional Nurse 1992;7:395-405. Kendrick AH, Smith EC. Interpretation of simple meas-
urements of lung function. Professional Nurse 1992;7:74854.
Barnes PJ, Chung KF, Evans TW, Spiro SG. Therapeutics $9 \begin{aligned} & \text { Barnes PJ, Chung KF, Evans TW, Spiro SG. Therapeutics } \\ & \text { in respiratory disease. London: Churchill Livingstone, } 1994 .\end{aligned}$ $10 \mathrm{H}$ Hosker HSR, Teale C, Greenstone MA, Muers MF. As-
sessment and provision of home nebulisers for chronic sessment and provision of home nebulisers for chronic
obstructive pulmonary disease (COPD) in the Yorkshire 